\title{
It's All about the Parents: Inequality Transmission across Three Generations in Sweden
}

\author{
Per Engzell, ${ }^{\mathrm{a}, \mathrm{b}}$ Carina Mood, ${ }^{\mathrm{b}, \mathrm{c}}$ Jan 0. Jonsson ${ }^{\mathrm{a}, \mathrm{b}, \mathrm{c}}$
}

\author{
a) University of Oxford; b) Stockholm University; c) Institute for Future Studies, Stockholm
}

\begin{abstract}
A recent literature studies the role of grandparents in status transmission. Results have been mixed, and theoretical contributions highlight biases that complicate the interpretation of these studies. We use newly harmonized income tax records on more than 700,000 Swedish lineages to establish four empirical facts. First, a model that includes both mothers and fathers and takes a multidimensional view of stratification reduces the residual three-generation association in our population to a trivial size. Second, data on fathers' cognitive ability show that even extensive controls for standard socioeconomic variables fail to remove omitted variable bias. Third, the common finding that grandparents compensate poor parental resources can be attributed to greater difficulty of observing parent status accurately at the lower end of the distribution. Fourth, the lower the data quality, and the less detailed the model, the greater is the size of the estimated grandparent coefficient. Future work on multigenerational mobility should pay less attention to the size and significance of this association, which depends heavily on arbitrary sample and specification characteristics, and go on to establish a set of more robust descriptive facts.
\end{abstract}

Keywords: social stratification; social mobility; multigenerational mobility; intergenerational income mobility; grandparent effects

Citation: Engzell, Per, Carina Mood, and Jan 0. Jonsson. 2020. "It's All about the Parents: Inequality Transmission across Three Generations in Sweden." Sociological Science 7: 242-267.

Received: March 24, 2020

Accepted: April 13, 2020

Published: June 1, 2020

Editor(s): Jesper Sørensen, Kim Weeden

DOI: $10.15195 /$ v7.a10

Copyright: (C) 2020 The Author(s). This open-access article has been published under a Creative Commons Attribution License, which allows unrestricted use, distribution and reproduction, in any form, as long as the original author and source have been credited. (0)(1)
STUDIES of the intergenerational transmission of economic status have a long $\checkmark$ history in the social sciences (e.g., Atkinson 1981; Sewell and Hauser 1975) and are of wide interest as they pertain to the broader societal ideal of equality of opportunity (e.g., Breen and Jonsson 2005; Erikson and Goldthorpe 1992). Such research confirms that in all known societies, the importance of having the right parents is substantial: despite quite widespread intergenerational mobility, access to higher social positions and incomes is strongly related to parental characteristics. Recent scholarship draws attention to limitations of the unidimensional models that permeate much of this literature. The standard one-parent one-offspring approach-typically using fathers' social class, income, or socioeconomic status to predict the same outcome among their children-risks underestimating long-run inequality transmission for at least three reasons: it neglects the influence of mothers (Beller 2009), of extended family members (Mare 2011), and of multiple stratifying dimensions (Mood 2017).

Especially, recent criticism targets the two-generation approach, where studies focus on parent-to-child associations. Following Mare's (2011) plea for multigenerational research, a growing number of studies consider grandparents' role in status attainment. Although results have been mixed, some of these studies report that incorporating prior generations into models improves predictions (e.g., Chan and Boliver 2013; Hällsten and Pfeffer 2017; Jæger 2012). A question that follows then is why this is the case. Is it that well-placed grandparents have a direct influence 
on their grandchildren? Or is it that grandparents' education, occupation, or income are correlated with unobserved attributes of parents that in turn aid their children's success? Existing research has tended to take the first interpretation. But this conclusion is weakened if we cannot observe everything about parents that matters. In particular, if mothers or multiple dimensions of status are ignored, the influence of grandparents may be overstated. A comprehensive assessment of what grandparents bring therefore requires expanding the model along more than one dimension.

Often, previous work acknowledges this and attempts to adjust for the potential confounding mechanisms. However, wide variation in the type and quality of available data makes it difficult to know whether the range of resulting estimates are the consequence of geographic and institutional variation, data availability, modeling choices, or something else. A recent review by Anderson, Sheppard, and Monden (2018) finds that in published work, study characteristics such as the number and detail of parental stratification indicators observed have no relation to the likelihood of detecting an independent grandparent effect. This might suggest that multigenerational advantage is largely unrelated to these other dimensions of stratification. At the same time, published studies do not represent a random sample of the universe of possible analyses. It could be that studies with different data and model characteristics also differ in other respects, which should make us wary of overinterpreting these differences between studies.

To understand why family status tends to persist across more than two generations, we need a better grasp of what underlies the conflicting results in the literature. Our aim here is to provide a systematic account where a wide range of possible models are applied to the same data set. By holding the population and institutional setting constant, we can learn precisely what influence data quality and modeling are likely to have on results. We focus on contemporary Sweden, where the available data are more fine-grained than elsewhere. Comprehensive population and taxation registers allow us to trace complete lineages and follow three generations over a significant part of each generation's life course. This, together with detailed and exhaustive information on common status indicators, makes a selection-on-observables strategy more plausible here than almost anywhere else. Our analysis has three steps. First, we establish a set of baseline results using a wide range of socioeconomic variables. Thereafter, we assess heterogeneity in the grandparent association and test for remaining omitted variable bias. Lastly, we gradually coarsen our data and model to ask whether data-driven reasons can account for the mixed results in the field.

The baseline model that we begin with improves on previous work in three important respects by 1) taking a fully multidimensional view of stratification studying income, class, education, and wealth in the same model; 2) assuming that mothers and fathers matter, among both parents and grandparents; and 3) measuring variables with unusual reliability. We focus on earnings in the grandchild generation, as we think that genuine grandparent effects are more plausible here than for other status outcomes that are causally upstream. Earnings subsume not only the cumulative advantage of education and social class attainment, but also advantages within occupations, for example through reputation or social networks where grandpar- 
ents have been postulated to matter. Adjusting for parents' education, occupation, and earnings, we find a small but significant remaining association between grandparent income and grandchild earnings; for other outcomes-cognitive tests, school grades, educational attainment, and occupational prestige-the association is zero.

We then interrogate this residual association further. First, we consider heterogeneity: is the benefit of a well-placed grandparent most marked for those with parents of high or low status? Existing studies have framed this question as one of "reinforcing" and "compensating" mechanisms and generally found support for the latter: the residual association between grandparent and grandchild status tends to be strongest at low levels of parental status (Anderson et al. 2018). We replicate this finding in our data. However, mindful of the limitations of standard socioeconomic controls, we also perform a placebo analysis using fathers' cognitive test scores in late adolescence as an alternative outcome. A virtually identical pattern appears but with associations of up to twice the size, suggesting a more mundane explanation: standard socioeconomic controls do not pick up all relevant differences between parents, and this error is especially grave at low levels of observed parental status.

Having established that the direct grandparent influence in our data is likely small or zero, we then turn our eye toward the wider literature and ask to what extent the variety of results reported therein can be attributed to incomplete parentto-child models. To this end, we coarsen our data to the quality typical of existing studies and see how results change. Introducing realistic errors of observation and reducing the model dimensions creates net grandparent associations several times larger than our initial estimates and covering much of the range of established results. We conclude that previous studies are likely to have exaggerated grandparents' importance. Should our interest in the extended family as a source of stratification be abandoned then? We end on a cautious note arguing that, although multivariate regression modeling of "grandparent effects" has yielded limited useful knowledge, the wider study of multigenerational mobility will continue to provide valuable insights into processes of stratification.

\section{The Case for Grandparents}

Why might a status attainment model without grandparents be incomplete? Multigenerational status transmission has concerned stratification scholars throughout the field's past (Mukherjee 1954; Pohl and Soleilhavoup 1982; Svalastoga 1959; Warren and Hauser 1997). Although there are different ways to approach this question, most previous research is couched in terms of the "Markovian" question (Hodge 1966): do grandparents affect their grandchildren's attainment directly, or is all influence mediated through parents? With increasing data availability, the number of such studies has grown almost exponentially in recent years (Anderson et al. 2018).

A range of social, economic, and psychological mechanisms make it plausible that grandparents should matter. The fact that we live longer and healthier means that grandparents can provide cultural, social, and economic resources until old age (Mare 2011; Pilkauskas and Cross 2018). In some societies, grandparents also co-reside with grandchildren, which may reinforce socialization effects (Zeng and 
Xie 2014). Many social institutions distribute positions and rewards based on family connections that can outlast a single life. Legacy admissions to U.S. universities are one such example, as is the putative value of having a good name in high-status occupations (Knigge 2016; Mare 2011). Tax on inheritance may, as used to be the case in Sweden, make it profitable to give money to grandchildren rather than letting the children inherit it.

Despite its theoretical appeal, the idea that grandparents matter has found mixed support (Anderson et al. 2018). Furthermore, partly because of different analytical strategies, authors come to different conclusions based on similar results or sometimes the same data. For example, Warren and Hauser's (1997:561) analysis of the Wisconsin Longitudinal Study found that "schooling, occupational status, and income of grandparents have few significant effects on the educational attainment or occupational status of their grandchildren when parents' characteristics are controlled." Using the same data, Jæger (2012:903) concluded that "the total effect of family background on educational success originates in the immediate family, the extended family, and in interactions between these two family environments."

Previous evidence from Sweden is similarly mixed. Some studies report grandparent effects, although not necessarily for all dimensions (e.g., Dribe and Helgertz 2016; Lindahl et al. 2015; Modin, Erikson, and Vågerö 2013; Modin and Fritzell 2009), whereas others find no or small effects (Stuhler 2014). Our data span cohorts born in the 1960s and early 1970s, their parents, and their grandparents. The index generation, the grandchildren, grew up during the heyday of the welfare state, which may have reduced the role of grandparents. On the other hand, income inequality was much greater in the grandparent than in the parent generation, so it is also possible that privileged grandparents had the opportunity to make a difference for their grandchildren.

\section{The Multigenerational Model}

What is the basis for claims made about grandparents in the literature? First, consider a simple two-generation model where a person's attained status $y_{C}$ is a function of his or her parents' status, $y_{P}$ :

$$
y_{C}=\alpha+\beta y_{P}+u \text {. }
$$

In this model, $y$ may be a measure of education, occupation, or income. We use $P$ and $C$ to index parent and child generations-and later, GP to refer to the grandparents. The interpretation of $\beta$ in this model is not causal: estimates tell us little about whether manipulating $y_{P}$, for example, by raising parents' education or redistributing income, would change $y_{C}$ by any amount. Instead, $\beta$ reflects a bundle of parental characteristics, including genes and a combination of cultural, social, economic, and other resources, as well as similarities across generations in structural locations, such as area of residence or ethnic group. Yet, we care about $\beta$ because how strongly advantage is transmitted is important regardless of 
how that transmission comes about. Now, let us turn to a model that incorporates grandparent status, $y_{G P}$ :

$$
y_{C}=\alpha+\beta_{P} y_{P}+\beta_{G P} y_{G P}+u .
$$

Here, $\beta_{G P}$ should, just as was the case for $\beta$, not be treated as a causal effect of a given GP characteristic, but as a proxy for a bundle of GP characteristics. However, unlike $\beta$ in Eq. (1), $\beta_{G P}$ is a conditional effect, and its size depends heavily on how $y_{P}$ is defined and measured. In general, the simpler the parental model, the more factors are left in the residual to be picked up by the GP coefficient in the model. To interpret $\beta_{G P}$ as a measure of GP influence therefore requires a leap of faith. Indeed, given how much parents provide children with (all the child's genes, nearly all primary socialization), it would seem safer to assume that $y_{G P}$ proxies for unobserved characteristics of $P$ rather than GP. Of course, most previous studies acknowledge this and add a more or less comprehensive conditioning set of parental variables $X_{P}$ :

$$
y_{C}=\alpha+\beta_{P} y_{P}+\beta_{G P} y_{G P}+\gamma X_{P}+u \text {. }
$$

However, the list of control variables is never exhaustive, and a wide variation in them makes it difficult to compare results across studies (Anderson et al. 2018). The question we ask here is simple: how would common estimates of $\beta_{G P}$ change in a model that takes all observable aspects of $P$ and GP status into account, including the long-run earnings or income of both mothers and fathers, as well as their education, occupation, and wealth? By linking and harmonizing Swedish population records, we have constructed a data set that allows us to do so. We use ordinary least squares to estimate Eq. (3) but include an unusually rich set of conditioning variables $X_{P}$, as well as a comprehensive coverage of grandparent resources. We also use cognitive tests from the military draft for a subsample of fathers to assess the sign of remaining confounding. In a last step, we then go on to show exactly how reducing the detail and dimension of $X_{P}$ affects results.

\section{Possible Biases}

In estimating the parameters of Eq. (3), several biases, typically stemming from data limitations, need to be taken into account. Table 1 summarizes the sources of bias we consider, and we elaborate on how we address each of them below.

\section{Ignoring Multidimensionality}

Different indicators such as education, occupation, and income tend to be positively but imperfectly correlated. Yet all of them predict children's outcomes, net of the others. Mood (2017), for example, shows that parents' social class and income contribute independently to predicting children's earnings. Moreover, class and income are both linked to social origin, as incumbents from higher-class origins usually enjoy an earnings advantage within a given class (Laurison and Friedman 
2016). For this reason, an analysis of the transmission of class only in three generations will attribute some of the advantage associated with $P$ income (which is not observed) to GP social class (which is). A similar argument would apply to studies that analyze income transmission without accounting for class or studies that focus exclusively on some third dimension such as education (e.g., Liu 2018; Song and Mare 2017). In our analysis, we model the multidimensionality of status explicitly by incorporating income, education, occupation, and wealth in the same model.

\section{Ignoring Mothers}

In two-generation studies of the past it was common to assign household status based on a male breadwinner, to the neglect of mothers. Subsequently, Erikson (1984) introduced the "dominance approach" where the spouse with the strongest connection to the labor market, and the higher occupation/class, got to represent the household's socioeconomic position. More recent research has shown either approach that leaves out one spouse (usually the woman) to be untenable (Beller 2009; Hout 2018; Mood 2017). Nevertheless, as Song and Mare (2017) point out, the neglect of mothers tends to continue in multigenerational research. In such cases, multigenerational associations may be confounded with the fact that both mothers and fathers contribute to their children's attainment. We avoid this problem by including both mothers and fathers in the GP and $P$ generations.

\section{Ignoring Measurement Error}

Measurement error is ubiquitous in survey data. Although the received wisdom about mismeasured predictors is that they bias associations downwards, in the multivariate case the opposite is often true: measurement error in an independent variable will lead some of its association to "spill over" to any correlated variables that appear together on the right-hand side of the equation (Bohrnstedt and Carter 1971). A common reason for error in survey data is that respondents are fallible and misreport. Another is the use of proxy variables like homeownership for wealth or annual instead of lifetime income. Problems compound when measures are limited in detail: income is often reported in banded form, or education and occupation collapsed into broader groups. In our case, use of register data means that we greatly reduce measurement error; education, for example, is constructed from school records with very high coverage, and incomes are gathered from tax records over several years. Because reports on $G P, P$, and $C$ are assembled independently we can also rule out measurement errors stemming from indirect reporting (e.g., by a spouse, or one generation reporting on the other).

\section{Incomplete Grandparent Data}

In contrast to the previous cases, $\beta_{G P}$ might be underestimated if data on GP are more limited than those on $P$. Due to data availability, the number and quality of variables in existing studies tend to be biased in favor of the $P$ generation. For one thing, data often come in several dimensions on parents but only as a single proxy for grandparents, and some information—such as income-is notoriously difficult 
Table 1: Overview of expected biases in the GP coefficient.

\begin{tabular}{|c|c|c|c|c|c|c|}
\hline & $\begin{array}{l}\text { Ignoring } \\
\text { multidimen- } \\
\text { sionality }\end{array}$ & $\begin{array}{l}\text { Ignoring } \\
\text { mothers }\end{array}$ & $\begin{array}{l}\text { Ignoring } \\
\text { measurement } \\
\text { error }\end{array}$ & $\begin{array}{l}\text { Incomplete } \\
\text { GP data }\end{array}$ & $\begin{array}{c}\text { Residual } \\
\text { confounding }\end{array}$ & $\begin{array}{c}\text { Collider } \\
\text { bias }\end{array}$ \\
\hline Expected direction of bias & + & + & + & - & + & - \\
\hline
\end{tabular}

to get retrospectively. A more subtle difficulty is that if a single person is used to index each generation, then that person will account for a smaller proportion of potential influencers in the GP generation (being one of four grandparents) than in the $P$ generation. Measurement error might be larger for $G P$ than $P$ if retrospective reports are used; this could both increase or decrease net GP associations, however, as such error is often not random. In our data, we have been able to include extensive, comparable indicators for all four grandparents (income, wealth, education, and occupation), and we take pains to assure as good coverage as possible in these respects.

\section{Residual Confounding}

There are several additional channels of transmission that might lead us to overestimate $\beta_{G P}$ : virtually any unobserved trait of the parents or family environment that both is shaped by parents' origins and predicts children's success. Examples include parents' cognitive and noncognitive skills; parental involvement and parenting "styles;" language codes, habitus, and cultural capital; values regarding the relative importance of economic success; beliefs about children's ability and what children should be expected to do; parental control and social closure; or the socioemotional climate of the family. Insofar as genetic transmission matters for status attainment, this is an unobserved variable that pertains wholly to the parental level. Another omitted factor that can create a spurious GP association is group attributes common to grandparents and children, such as minority status. As we exclude anyone with a family presence in Sweden shorter than three generations, our population is relatively ethnically homogeneous. However, we do address the role of skills and abilities in the $P$ generation by using fathers' cognitive test scores from conscription as a placebo outcome as we describe next.

\section{Collider Bias}

Although the potential of an inflated positive $\beta_{G P}$ due to unmeasured parental characteristics is rather intuitive, there is a less intuitive mechanism that can, at least in theory, operate in the other direction and suppress a positive $\beta_{G P}$. It has recently become common to talk of this as "collider bias" (Breen 2018; Pearl 2000; Song 2016), whereas an older term is Berkson's paradox (Berkson 1946; Pearce and Richiardi 2014). In the intergenerational literature, the mechanism has been noticed by Becker and Tomes (1979:1171; cf. Goldberger 1989: Section V; Solon 2014). One way to understand it is as an interaction between $y_{G P}$ and $y_{P}$ : observations with a given 
$y_{P}$ but different $y_{G P}$ may not be exchangeable, because parents who arrived at $y_{P}$ through a process of downward (upward) mobility could be negatively (positively) selected on some unobserved trait. Once transmitted to children, this trait will be picked up by $\beta_{G P}$ and suppress it towards the null. Assuming that fathers' cognitive ability belongs to this list of potential unobserved confounders, our inclusion of it as a placebo outcome tests this argument: if there is collider bias, we would expect it to show a negative correlation with GP status at given levels of $P$ status. If the correlation is the same sign as for children's status, positive, it implies that residual confounding is dominant over collider bias.

\section{Data and Definitions}

Our data are from Swedish population registers and Census microdata that cover the entire population up to age 75. We focus on Swedish-born men and women (the grandchild generation, C) born from 1965 to 1972. Each individual is linked to biological and any adoptive parents and grandparents using a multigenerational identifier. The matching, done by Statistics Sweden, is entirely accurate, but age limits and mortality in the data mean that we cannot match all grandparents. In the 1965 cohort we cover 46 percent of paternal grandfathers and 73 percent of maternal grandmothers, but coverage increases over cohorts. In the 1972 cohort we cover 69 percent of paternal grandfathers and 89 percent of maternal grandmothers (see Table S1 in the online supplement). In both generations, adoptive parents are given priority over biological parents if both exist in the data, so a child can have only one set of parents. In the case of adoptive parents, their parents are also defined as grandparents. As is the case in all three-generation models, we must exclude index persons whose parents were not born in Sweden or cases where all grandparents were born abroad. We keep all persons who can be linked to at least one parent and at least one grandparent.

The outcome variable in our main analyses is child yearly earnings from employment, self-employment, and earnings-related benefits (e.g., sickness or parenting benefits), averaged over ages 35 to 40 . Earnings that are more than four standard deviations higher than the average in a given year (around 0.3 percent) are top-coded. The variable is missing-coded if earnings are missing in more than two years in the 35-to-40 age span, and the final variable is $z$-standardized within each cohort and for men and women separately. Our focus is on earnings, but we show results on other outcomes as well: occupational prestige, educational attainment, school grades, and enlistment test scores. Earnings are, however, a conceptually attractive outcome. As a relatively final marker of success, it subsumes the impact of both education and occupation (Mood 2017). It also lets us cover extended family influence-through social networks, for example-in the labor market (cf. Knigge 2016) and is more normally distributed than wealth (Killewald, Pfeffer, and Schachner 2017).

The main predictor in the GP generation is income, constructed as follows: For each year, 1968 to 1972, we define the disposable family income of each of the four grandparents as the within-family sum of all incomes (net of taxes). Zero and negative incomes ( 0.6 percent of the sample) are missing-coded, and incomes above four standard deviations are top-coded. We then standardize this variable (mean 0 , 
standard deviation 1) within groups based on grandparents' birth cohort and sex. We take the average over the years 1968 to 1972 for each grandparent and repeat this procedure across all grandparents. If any grandparent is missing, the nonmissing ones are used. By observing all grandparent incomes during the same time period we eliminate differences due to changes in taxation and available benefits, and by standardizing within cohort we neutralize the impact of grandparental age differences.

Our main interest is in the net association between GP income and $C$ earnings, varying the range of parental attributes that the model conditions on. As control variables in the $P$ generation, we use the income, education (level and field of study), social class, occupation, and wealth of both parents as described in detail below.

Mother earnings and father earnings are defined as annual earnings, including earnings-related benefits, averaged over ages 44 to 55 . Before taking the average, annual earnings are $z$-standardized by calendar year, cohort, and sex, and earnings above four standard deviations are top-coded. We construct parental earnings as the average of mother and father earnings.

Parental social class is coded from records about occupation in the Censuses of 1960, 1970, 1975, 1980,1985, and 1990. Priority is given to the occupations that the parents held when the child was aged 10 to 15 . All censuses are, however, used in order to get as many nonmissing records as possible. Class mobility among adults is low (Jonsson, 2001), so this procedure is unlikely to be problematic. Occupations are coded into 82 microclasses (Jonsson et al. 2009) and seven Erikson-Goldthorpe (EGP) classes: I = upper middle class (professionals, higher administrative, executives), II = middle class (semiprofessionals [e.g., nurses], midlevel administrative, low-level managers), III = routine nonmanual (clerks, secretaries, office workers), IV = self-employed, $\mathrm{V}=$ farmers, $\mathrm{VI}=$ skilled manual workers, and VII = unskilled manual workers (Erikson and Goldthorpe 1992).

Parental education is included for each of the parents separately, measuring level and field for the highest completed level of education (the International Standard Classification of Education [ISCED], 47 categories) according to the education register. We use the most recent information available (later information is more reliable due to revisions of the register).

Parental wealth is measured for each parent as the average net worth of the five "best" years between 1968 and 1989, that is, the years with the highest registered taxable wealth. The average of the mother's and father's wealth is then top-coded at four standard deviations above the mean within each cohort and standardized per cohort. We also tested wealth defined as the average over the whole period or for two subperiods with very different taxation limits (1968-1977; 1978-1989), and as categories, but the chosen definition had the strongest association with child earnings.

In additional analyses, we also include GP social class (EGP) and wealth. Both are measured identically to that of parents, class in the Censuses of 1960,1970, and 1975, and GP wealth in 1968 through 1989. GP education is measured with a slightly reduced, five-category, variable due to the smaller variation in education in the older cohorts. In analyses in the online supplement, child occupation is measured as the Standard International Occupational Prestige Scale (SIOPS; Treiman 1977), 
with priority given to the occupation held at ages 38 to 42 , and child education is measured in years as estimated from educational level and field. For the 1972 cohort, we also include child school grades, measured as the average of all grades received at age 15 . For men, we include cognitive test results from the military draft at age 18.

As control variables, all analyses also include child cohort dummies and the age of parents and grandparents together with its square term. Parents' age is measured as the average over both parents at the child's year of birth (on average, fathers are three years older than mothers, the gap decreasing from 3.3 to 2.7 years from cohort 1965 to 1972). Extreme values (normally due to adoptions) are missing-coded. GP age is measured in 1970 as an average of the age of all grandparents recorded in the data. The number of valid observations is displayed in Table S1 in the online supplement and ranges from 87,977 to 95,574 per cohort, resulting in an $\mathrm{N}$ of 733,913 in total (51 percent men). Table S2 in the online supplement assesses robustness of results to differential selection of grandparents by estimating our main results for each cohort separately.

\section{Baseline Results}

A first look at intergenerational associations is provided in Figure 1, which plots expected child earnings (in standard deviations) by child gender at each percentile of $P$ and GP income. For the GP-C association, we distinguish between the unconditional expectation and that after conditioning on parent attributes: earnings, occupation, and wealth. The graph superimposes the least-squares lines of best linear fit for each association. Corresponding regression results are provided in Table 2 (upper half). All income and earnings variables are standardized, so coefficients can be interpreted as correlations.

\section{Two- and Three-Generation Associations}

Our regression of child earnings on parent earnings (Figure 1, Table 2) yields a correlation of 0.29 (men, 0.30; women, 0.27 ), broadly in line with previous twogeneration research for Sweden, and implying that one standard deviation earnings difference among parents translates into an expected difference in the child generation of slightly more than a fourth of a standard deviation. Although it is not shown in Figure 1, the GP-P association is higher at 0.35 , a third of a standard deviation, which may represent an equalization over historical time in the intergenerational transmission of inequality in Sweden (although we must caution against the difference in sample characteristics).

If income transmission were a unidimensional Markov process-independent of class, education, or wealth-we would expect the bivariate association GP-C to amount to a mere $0.08\left(0.29^{2}\right)$. The GP-C association we observe is much stronger and roughly half the size of the $P-C$ association (men, 0.16 ; women, 0.13 ). This ratio is similar to previous three-generation studies for Sweden (Adermon, Lindahl, and Palme 2019; Adermon, Lindahl, and Waldenström 2018; Lindahl et al. 2015). 


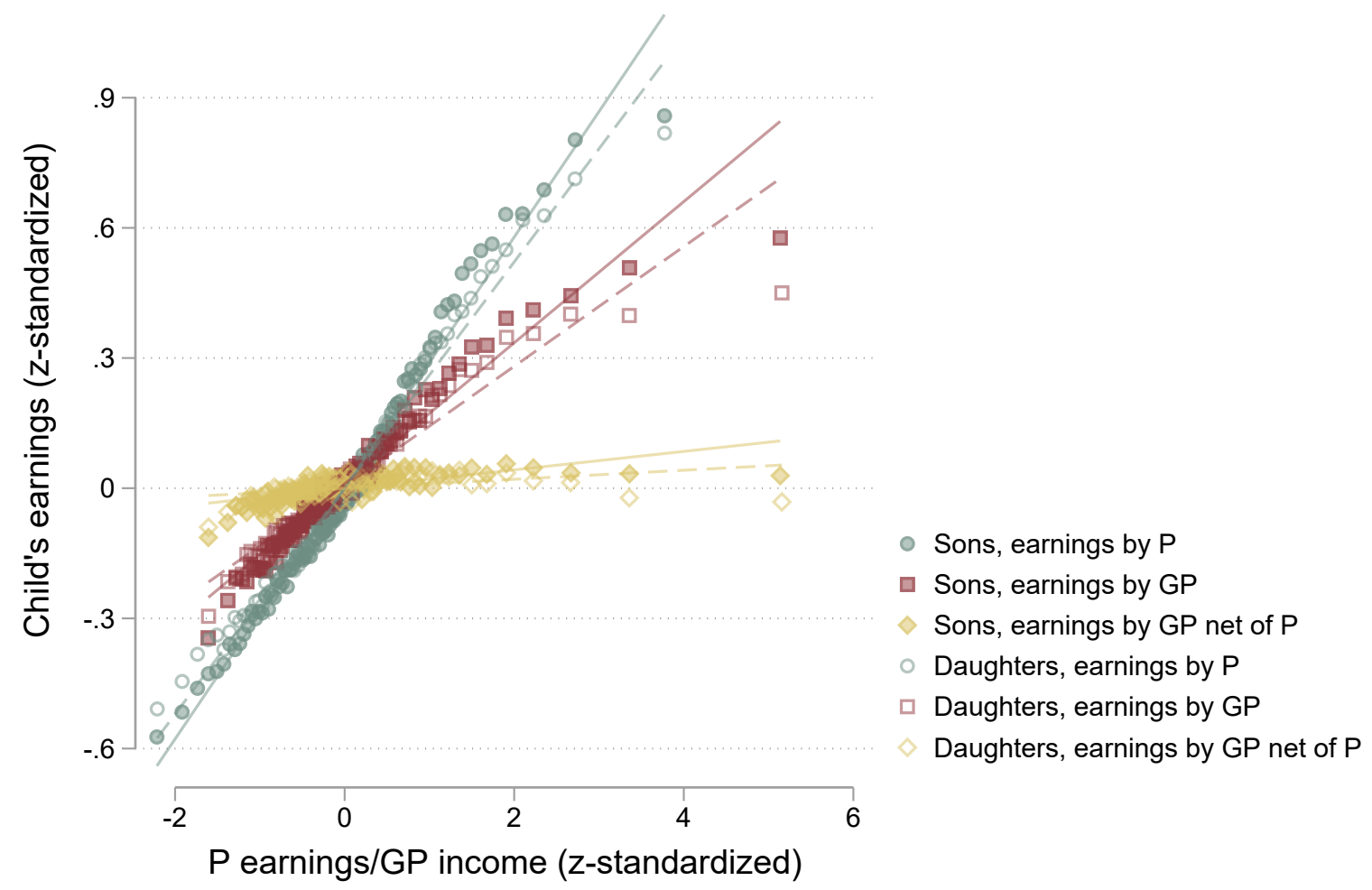

Figure 1: Associations between $P$ and $C$ earnings, and $G P$ income and $C$ earnings with and without $P$ controls. Note: The figure shows expected $C$ earnings at each percentile of $P$ earnings and GP income, separated by $C$ gender. Estimates for the GP association are shown before (red) and after (yellow) adjusting for covariates: earnings, education, and wealth of both parents; parent age and age squared; and child birth cohort. Overlaid regression lines are estimated on the underlying (ungrouped) data; dashed lines for women, solid for men. Income and earnings have been standardized within calendar year, cohort, and gender. Regression estimates are reported in Table 2 (upper half). $\mathrm{N}=359,885$ sons; 340,866 daughters.

\section{Residual Three-Generation Associations}

Our next question is what happens to the GP-C association once we condition on parent attributes, and the answer is that it shrinks dramatically. When controlling for parental earnings, the GP coefficient is reduced to 0.07 (men) and 0.05 (women). However, controlling only for earnings is an insufficient representation of what parents bring to the dyadic relation with their children. Two-generation models typically acknowledge, beside economic factors, the importance of educational, social, and cultural resources, as well as the strong inclination of children to follow in their parents' footsteps in terms of occupations and social class attainment (e.g., Erikson and Goldthorpe 1992; Jonsson et al. 2009; Sewell and Hauser 1975). In line with this, the last set of estimates in Figure 1 show the GP-C association after controlling for parents' earnings, education, class, occupation, and wealthpredictors that all have net positive associations with child incomes (Mood 2017). 
Table 2: Regression results underlying displays in Figures 1 and 2.

\begin{tabular}{|c|c|c|c|c|c|c|c|c|}
\hline & \multicolumn{4}{|c|}{ Son's earnings $(\mathrm{N}=359,885)$} & \multicolumn{4}{|c|}{ Daughter's earnings $(\mathrm{N}=340,866)$} \\
\hline & $\begin{array}{l}\text { Only GP } \\
\text { income }\end{array}$ & $\begin{array}{l}\text { Only } P \\
\text { earnings }\end{array}$ & $\begin{array}{l}G P+P \\
\text { earnings }\end{array}$ & $\begin{array}{l}G P+\text { full } P \\
\text { controls }\end{array}$ & $\begin{array}{l}\text { Only GP } \\
\text { income }\end{array}$ & $\begin{array}{l}\text { Only } P \\
\text { earnings }\end{array}$ & $\begin{array}{l}G P+P \\
\text { earnings }\end{array}$ & $\begin{array}{l}G P+\text { full } P \\
\text { controls }\end{array}$ \\
\hline Grandparent income & 0.163 & & 0.065 & 0.027 & 0.137 & & 0.047 & 0.013 \\
\hline Parent earnings & & 0.302 & 0.278 & & & 0.274 & 0.257 & \\
\hline Father earnings & & & & 0.157 & & & & 0.108 \\
\hline Mother earnings & & & & 0.083 & & & & 0.114 \\
\hline All parent controls & & & & Yes & & & & Yes \\
\hline \multirow[t]{3}{*}{ R-squared } & 0.026 & 0.087 & 0.091 & 0.116 & 0.019 & 0.071 & 0.073 & 0.092 \\
\hline & \multicolumn{4}{|c|}{ Son's earnings $(\mathrm{N}=396,473)$} & \multicolumn{4}{|c|}{ Daughter's earnings ( $N=375,251)$} \\
\hline & $\begin{array}{l}\text { Only } G F \\
\text { EGP }\end{array}$ & $\begin{array}{l}\text { Only } F \\
\text { EGP }\end{array}$ & $\begin{array}{l}G F+F \\
\mathrm{EGP}\end{array}$ & $\begin{array}{l}\text { GF EGP + full } \\
\text { controls }\end{array}$ & $\begin{array}{l}\text { Only GF } \\
\text { EGP }\end{array}$ & $\begin{array}{l}\text { Only } F \\
\text { EGP }\end{array}$ & $\begin{array}{l}G F+F \\
\text { EGP }\end{array}$ & $\begin{array}{l}\text { GF EGP + full } \\
\text { controls }\end{array}$ \\
\hline $\begin{array}{l}\text { Paternal grandfather } \\
\text { EGP } \\
\text { (ref upper service class) }\end{array}$ & & & & & & & & \\
\hline Mid service & -0.175 & & -0.115 & -0.039 & -0.147 & & -0.085 & -0.013 \\
\hline Low nonmanual & -0.278 & & -0.143 & -0.041 & -0.249 & & -0.121 & -0.019 \\
\hline Self-employed & -0.321 & & -0.145 & -0.048 & -0.279 & & -0.121 & -0.023 \\
\hline Farmers & -0.380 & & -0.135 & -0.034 & -0.309 & & -0.111 & -0.009 \\
\hline Skilled manual & -0.406 & & -0.203 & -0.070 & -0.350 & & -0.168 & -0.037 \\
\hline Nonskilled manual & -0.448 & & -0.220 & -0.073 & -0.393 & & -0.189 & -0.044 \\
\hline Missing occupation & -0.378 & & -0.193 & -0.080 & -0.297 & & -0.135 & -0.028 \\
\hline Not in census & -0.421 & & -0.222 & -0.089 & -0.334 & & -0.163 & -0.048 \\
\hline $\begin{array}{l}\text { Father EGP } \\
\text { (ref upper service class) }\end{array}$ & & & & & & & & \\
\hline Mid service & & -0.251 & -0.236 & & & -0.237 & -0.223 & \\
\hline Low nonmanual & & -0.412 & -0.391 & & & -0.378 & -0.360 & \\
\hline Self-employed & & -0.519 & -0.501 & & & -0.456 & -0.440 & \\
\hline Farmers & & -0.677 & -0.656 & & & -0.438 & -0.423 & \\
\hline Skilled manual & & -0.599 & -0.570 & & & -0.525 & -0.500 & \\
\hline Nonskilled manual & & -0.678 & -0.649 & & & -0.594 & -0.569 & \\
\hline Missing occupation & & -1.085 & -1.052 & & & -0.880 & -0.858 & \\
\hline All parent controls & & & & Yes & & & & Yes \\
\hline R-squared & 0.010 & 0.056 & 0.058 & 0.115 & 0.007 & 0.040 & 0.041 & 0.090 \\
\hline
\end{tabular}

Note: The table shows regressions of $C$ earnings on GP/P income (top) and GP/P social class (bottom), separated by $C$ gender. Income and earnings have been $z$-standardized so that regression coefficients can be interpreted as correlations. Full controls include the earnings, occupation, education, and wealth of both parents; parent age and age squared; and child birth cohort. $G F=$ grandfather, $F=$ father.

Once we consider this multidimensional nature of the parent-child relationship, the remaining GP-C association all but disappears: it is reduced to 0.03 for men and 0.01 for women.

\section{Additional Child Outcomes}

We have focused on child earnings, as we believe net grandparent associations to be more likely here than for causally upstream variables such as education. Earnings include the influence of education but also things like connections in the labor market, where a grandparent's social or reputational capital may matter. In Table 3, we introduce additional outcomes: occupational prestige, educational attainment, school grades, and cognitive test results. As in our earlier analyses, the main predictor is GP income, and $P$ covariates include the full set described 
Table 3: Regression analyses using alternative child outcomes.

\begin{tabular}{lcccc}
\hline & $\begin{array}{c}\text { Occupational } \\
\text { status (SIOPS) }\end{array}$ & $\begin{array}{c}\text { Years of } \\
\text { schooling }\end{array}$ & $\begin{array}{c}\text { School grades } \\
\text { (1972 cohort } \\
\text { only) }\end{array}$ & $\begin{array}{r}\text { Cognitive test } \\
\text { results (sons } \\
\text { only) }\end{array}$ \\
\hline Sons & & & & \\
$P$ earnings, bivariate & 0.285 & 0.314 & 0.309 & 0.213 \\
GP income, bivariate & 0.200 & 0.217 & 0.205 & 0.196 \\
GP income after P controls & 0.016 & -0.003 & -0.008 & -0.004 \\
N & 318,155 & 359,491 & 44,385 & 308,147 \\
\hline Daughters & & & & \\
P earnings, bivariate & 0.262 & 0.276 & 0.273 & \\
GP income, bivariate & 0.182 & 0.177 & 0.182 & \\
GP income after P controls & 0.005 & -0.015 & -0.015 & \\
N & 318,603 & 340,625 & 42,809 & \\
\hline
\end{tabular}

Note: The table shows regressions of various child outcomes on GP income and $P$ earnings, separated by $C$ gender. Outcomes and predictors have been $z$-standardized so that regression coefficients can be interpreted as correlations. Full controls include the earnings, occupation, education, and wealth of both parents; parent age and age squared; and child birth cohort. Occupational status is from age 38 to 42 for the majority of respondents. Years of schooling have been converted from the highest completed level of education (ISCED, 47 categories). School grades are the grade point average in the student's 16 best subjects at the end of compulsory school (age 15). Cognitive test results are from the military draft at age 18, which was mandatory for all men in these cohorts.

above. As expected, the net GP associations for these variables are even smaller: all within 0.01 to 0.02 decimal points from zero and in some cases negative. This is despite the fact that the relative size of the GP association without controls is large: about two-thirds the size of the $P$ earnings coefficient for occupation, education, and school grades, and more than 90 percent of the $P$ earnings coefficient for sons' cognitive test results from conscription, compared with a mere third in the earlier results for $C$ earnings.

\section{Additional Grandparent Predictors}

One implication of our multidimensional perspective is that not only will GP and $P$ income independently predict $C$ earnings, but so will GP and $P$ social class, or any other stratifying dimension. Figure 2 illustrates this, again using $C$ earnings as the outcome but with class as the status variable in prior generations-coded from the father's and paternal grandfather's occupation and grouped according to the EGP schema. Like before, we see a sizeable association over three generations, but little evidence of a net GP "effect" once differences among parents in additional dimensions are taken into account.

Could it be, however, that by focusing on one GP characteristic at a time while including the full range of $P$ controls, we unfairly tilt the playing field against grandparents? To test a fuller set of GP characteristics, we estimate a model that includes all four (when available) grandparents' income, education, social class, and wealth. Table 4 shows the R-squared from these regressions, before and after 


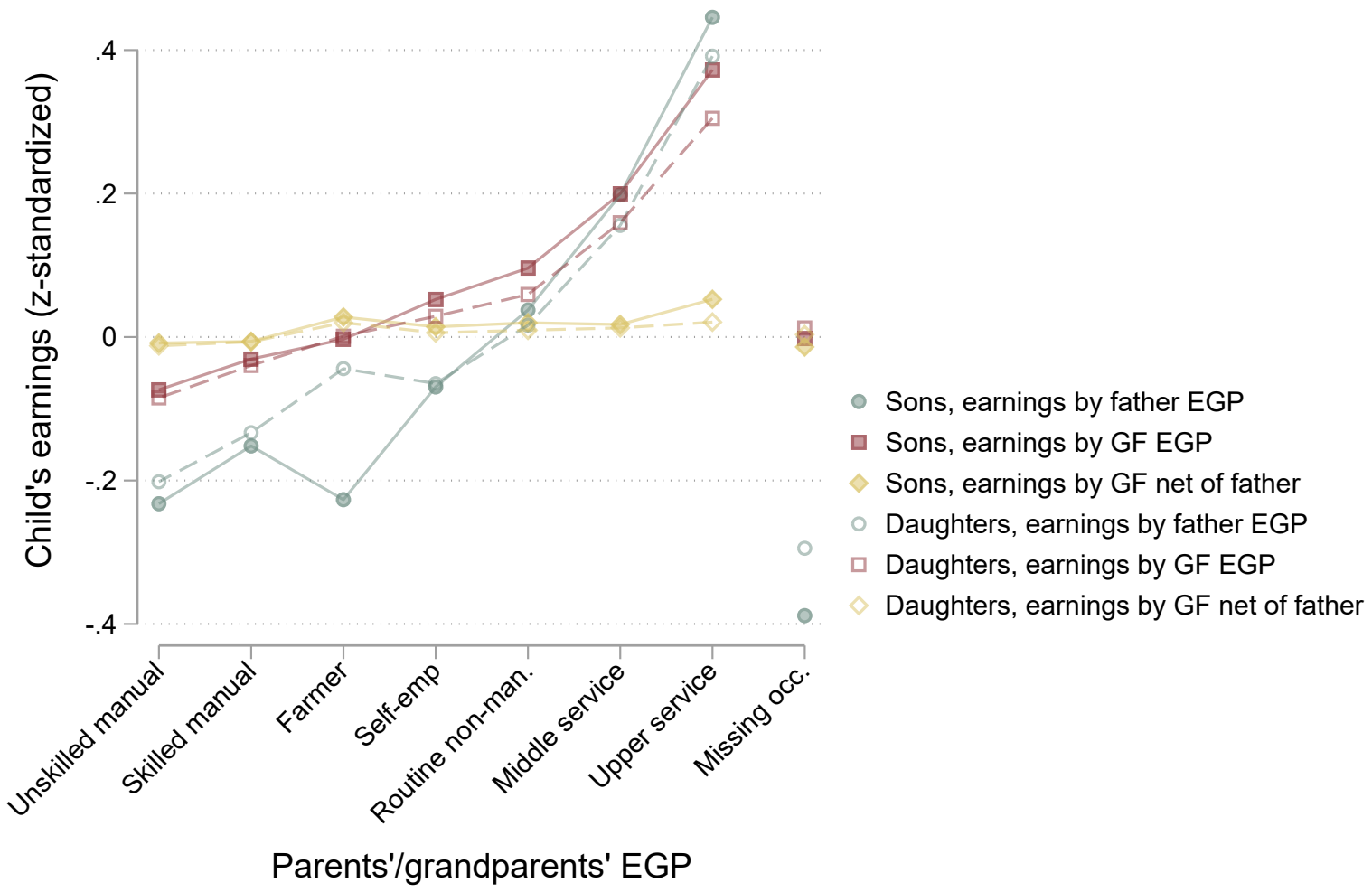

Figure 2: Associations between $P$ social class and child earnings, and GP social class and child earnings with and without $P$ controls. Note: The figure shows expected $C$ earnings at each value of $P$ and GP social class, separated by $C$ gender. Social class is coded from the father $(F)$ and paternal grandfather $(G F)$. Estimates for the GP association are shown before (red) and after (yellow) adjusting for covariates: earnings, education, and wealth of both parents; parent age and age squared; and child birth cohort. Markers are connected with dashed lines for women, solid for men. Earnings have been standardized within calendar year, cohort, and gender. Regression estimates are reported in Table 3 (lower half). N=396,473 sons; 375,251 daughters.

controlling for parental variables in their entire dimensionality. The contribution of the full set of GP indicators together in explaining adult grandchildren's income amounts to a fifth or a tenth of a percent of the total variance- that is, a modest amount. Thus, even taking a multitude of grandparental resources into account, with appropriate controls at the parental level, the $G P-P-C$ associations form an almost perfect Markov chain.

\section{Heterogeneity and Residual Confounding}

A common argument in the literature is that GP associations that are small on average may nevertheless hide pockets of inequality where a prominent grandparent matters more (Mare 2011; Pfeffer 2014). There is a strong theoretical argument for rich grandparents compensating their grandchildren when parents lack resources 
Table 4: R-squared from regressions of child earnings on full set of GP variables with and without $P$ controls.

\begin{tabular}{|c|c|c|c|c|}
\hline & \multicolumn{4}{|c|}{ R-squared } \\
\hline & $\begin{array}{l}\text { Grandparent } \\
\text { variables } \\
\text { only }\end{array}$ & $\begin{array}{c}\text { Parent } \\
\text { variables } \\
\text { only }\end{array}$ & $\begin{array}{l}\text { Parents and } \\
\text { grandparents }\end{array}$ & $\begin{array}{l}\text { Grandparent } \\
\text { contribution }\end{array}$ \\
\hline \multicolumn{5}{|l|}{ Sons } \\
\hline GP income, EGP, wealth, education & 0.039 & 0.115 & 0.117 & 0.002 \\
\hline$G P$ income & 0.026 & 0.115 & 0.116 & 0.001 \\
\hline GP EGP & 0.020 & 0.115 & 0.116 & 0.001 \\
\hline GP wealth & 0.014 & 0.115 & 0.116 & 0.001 \\
\hline GP education & 0.009 & 0.115 & 0.116 & 0.001 \\
\hline $\mathrm{N}$ & & & & 359,883 \\
\hline \multicolumn{5}{|l|}{$\overline{\text { Daughters }}$} \\
\hline GP income, EGP, wealth, education & 0.029 & 0.092 & 0.093 & 0.001 \\
\hline GP income & 0.019 & 0.092 & 0.092 & 0.000 \\
\hline GP EGP & 0.014 & 0.092 & 0.092 & 0.000 \\
\hline GP wealth & 0.010 & 0.092 & 0.092 & 0.000 \\
\hline GP education & 0.008 & 0.092 & 0.092 & 0.000 \\
\hline $\mathrm{N}$ & & & & 340,864 \\
\hline
\end{tabular}

Note: The table shows R-squared from a set of regressions analogous to those in Tables 2 and 3 but expanding the number of GP predictors to include the income, education, social class, and wealth of all four grandparents (when available). Full controls include the earnings, occupation, education, and wealth of both parents; parent age and age squared; and child birth cohort.

(e.g., Bengtson 2001; Song 2016) and some previous support for this (Anderson et al. 2018; Deindl and Tieben 2016; Jæger 2012). On the other hand, in two-generation models, economic advantages tend to be amplified at the higher end of parental resources (Björklund, Roine, and Waldenström 2012; Bratsberg et al. 2007).

We test for heterogeneity by letting the GP-C association vary by each tertile of $P$ total earnings. We then address remaining omitted variable bias by seeing whether parents with the same status but different levels of GP income are really comparable. To this end, we use fathers' cognitive test scores from military conscription at age 18. Draft records are only available from 1968, so we are left with a smaller subsample of 8,266 children, their parents, and their grandparents. Our reanalysis of $C$ earnings regressions by $P$ earnings bands closely resembles our earlier estimates for the full sample but reveals an additional result (Figure 3, top): net GP associations are almost exclusively concentrated to the bottom third of $P$ earners, in line with earlier results from this literature (Anderson et al. 2018).

Next we repeat the analysis with fathers' cognitive test results as the outcome (Figure 3, bottom). Despite extensive controls for both parents' education, occupation, and earnings, we find a similar pattern, roughly double in strength: GP income remains positively associated with fathers' conscription test scores, and this is most marked in the bottom third of $P$ earnings. We take this as evidence that even in our most extensively controlled model above, residual confounding remains nonnegligible. This leads us to refrain from interpreting the interaction between GP 

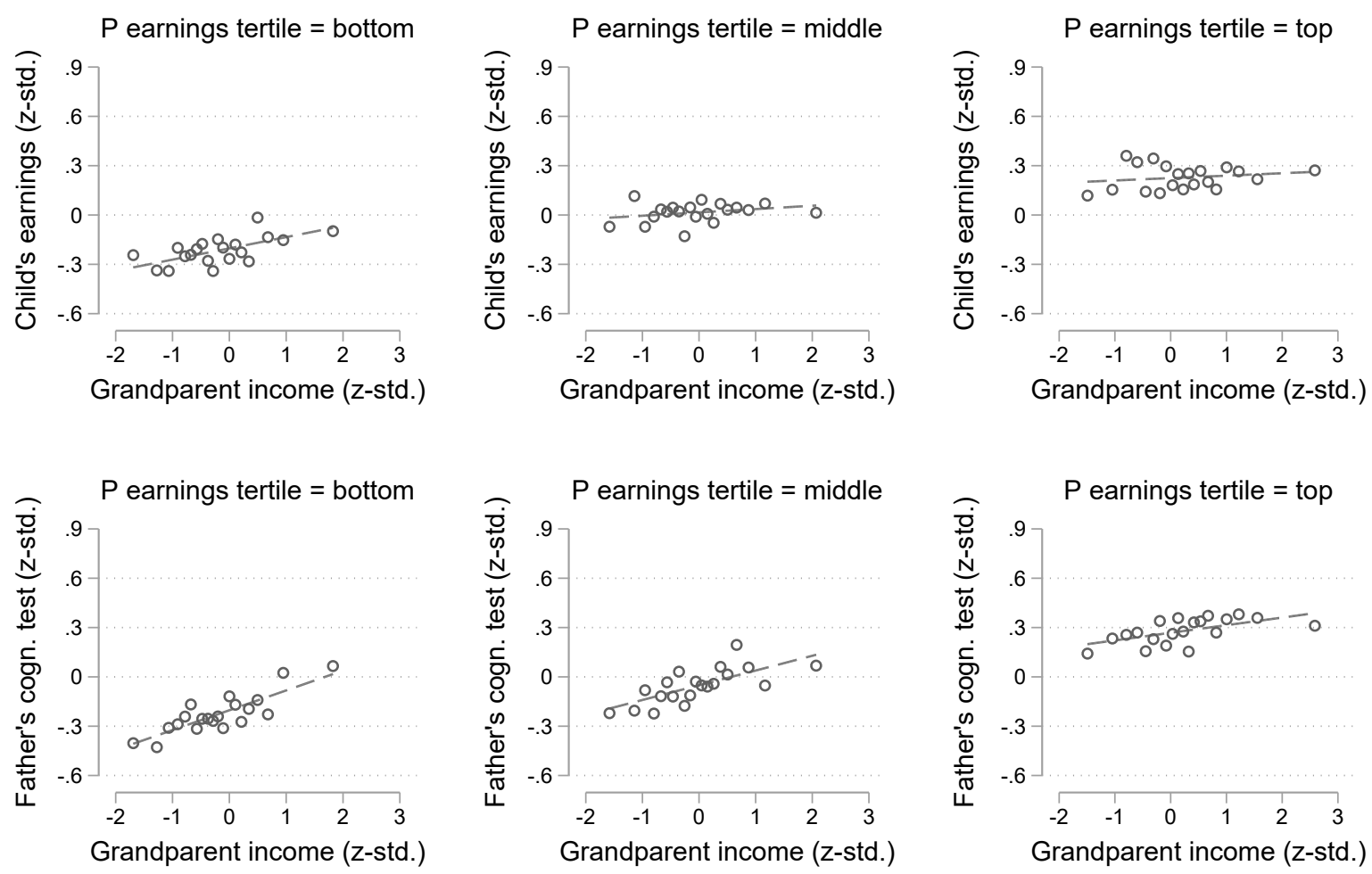

Figure 3: Net GP association with $C$ earnings and father cognitive score by $P$ earnings tertile, including full parental controls. Note: The figure shows net associations between GP income and C earnings (top panels) and using fathers' cognitive test scores as a placebo outcome (bottom panels), by tertiles of $P$ earnings. Cognitive test results are from fathers' military conscription at age 18 and restricted to fathers born after 1950. All associations adjust for earnings, education, and wealth of both parents; parent age and age squared; and child birth cohort. GP income has been binned into 20 equal frequency intervals; markers show the conditional mean within each. Regression lines of best fit are shown estimated on the underlying (ungrouped) data. Slope estimates for $C$ earnings are: 0.068 (top, left), 0.020 (top, middle), 0.014 (top, right), and for fathers' cognitive test scores: 0.121 (top, left), 0.089 (top, middle), 0.046 (top, right). $N=8,266$ children (sons and daughters).

and $P$ status as evidence that GP resources have a compensatory function at low levels of $P$ resources. Instead, a more plausible explanation seems to be that standard socioeconomic controls are not successful at absorbing all relevant differences between parents, and this is especially true at low levels of parental status.

\section{Explaining Variation in the Literature}

Our analyses so far show that taking a multidimensional view on advantage, including both mothers and fathers, and drawing on high quality register data with nearly no measurement error, reduce the net GP associations to a trivial size. Our analysis of fathers' conscription test scores as a placebo outcome suggests that the 
small net GP associations we are left with are still upwardly biased. Nevertheless, the question remains what explains the variety of results in earlier studies. The unique nature of our data means that we cannot extend our approach to other contexts. However, we can turn the question on its head by asking, what would the less well-measured models common in the literature make of our data? Keeping the population and institutional setting constant in this way, we learn precisely what influence data and model selection have on the results. In this exercise, we draw inspiration from recent approaches to multimodel inference (Simonsohn, Simmons, and Nelson 2015; Young and Holsteen 2017).

Existing studies sometimes fail to take a fully dimensional view of stratification, whereas we have done so by including every common status indicator in the same analysis. Now we successively exclude status dimensions in the $P$ generation to see how this impacts estimates. Consequently, we use the following seven sets of controls: (i) $P$ earnings, occupation, and education; (ii) $P$ earnings and occupation; (iii) $P$ earnings and education; (iv) $P$ occupation and education; (v) $P$ earnings only; (vi) $P$ occupation only; (vii) $P$ education only. Moreover, it is common to model patrilineal associations to the exclusion of mothers, and we therefore estimate models with (viii) and without (ix) mothers, increasing the number of models to $7 \times 2=14$ (each set of controls with and without mothers). Another source of bias we consider is measurement error in both detail and reliability, as we describe next.

Common for existing studies is that variables often appear in categorical form where much of the variation may be lost: three or four categories for education or occupation; quantiles for income or wealth. We distinguish three levels of detail: "high," "medium," and "low." High detail (x) refers to our full model above: the standardized total income of all grandparents, standardized earnings of the child and both parents, and father's and mother's educational level in 47 categories and occupation in 82 microclasses. For medium detail (xi), we rank-transform income and earnings measures for GP, $P, C$ and collapse $P$ education and occupation in broader categories: five categories for education (ISCED) and seven categories for occupation (EGP). Low detail (xii) has income and earnings for GP, $P, C$ transformed to quintiles and $P$ education and occupation as binary (respectively, college and service class versus all others). This further increases the model count to $14 \times 3=42$.

Our data also differ from common survey data sets in the amount of error. The fact that education measures are reported directly by educational institutions and incomes constructed from tax records over several years means that we almost wholly avoid the misreporting that hampers survey data. Therefore, we reestimate models with (xiii) no added error, (xiv) 10 percent noise, and (xv) 20 percent noise. Although the latter figure appears realistic for survey misreporting (Bingley and Martinello 2014; Breen and Jonsson 1997), it is still on the lower side as it does not account for additional sources of error, such as when substituting annual for lifetime income. We create the error-prone measures by pairing each observation with a randomly chosen match of the same gender, then averaging the two with weight $w=\{0,0.1,0.2\}$ assigned to the false value. For categorical variables, we randomly round up or down to the closest integer. These three scenarios lead to a final count of $42 \times 3=126$ models. For both the errors of detail and reliability, we apply the same standard to all three generations. 


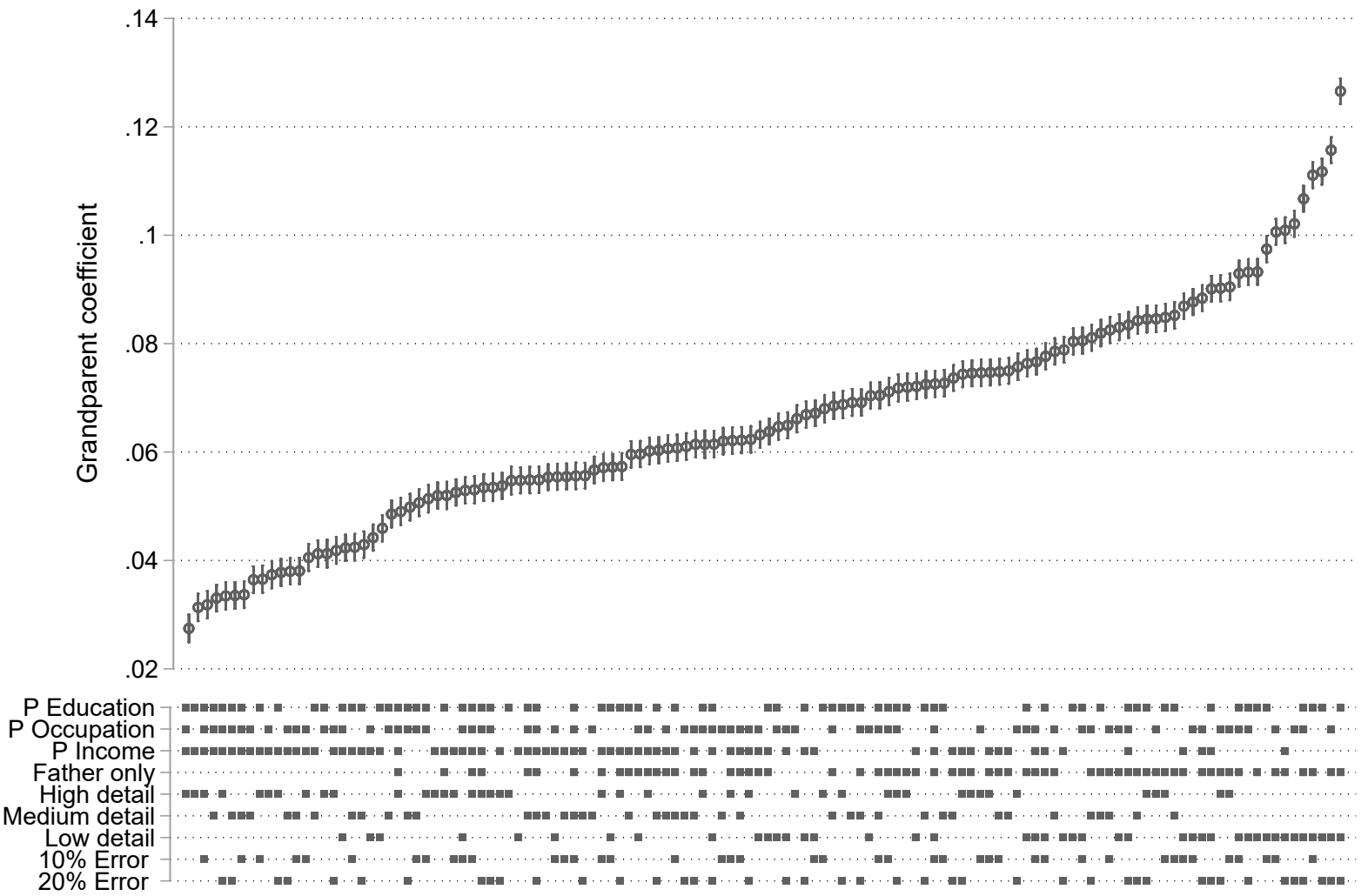

Figure 4: Net GP association with $C$ earnings from 126 models varying the model components. Note: The figure shows net associations between GP income and $C$ earnings from a set of 126 alternative models. Each estimate comes from a different model, where models are formed by varying the number of status dimensions (all or a subset of $P$ education, occupation, and earnings); parents covered (both or fathers only); level of measurement (high, medium, low); and imputed errors of observation (none, 10 percent, or 20 percent). Income and earnings have been $z$-standardized so that estimates reflect correlations. The bottom panel displays the combination of components for each model. Models with lower detail and reliability apply the same standard to all three generations $(G P, P, C)$. Our preferred model is the leftmost one, which includes controls for the earnings, occupation, and education of both parents at the most detailed level of observation, and with no error added. All models additionally include controls for parent age and age squared, and child birth cohort and gender. Error bars display 95 percent confidence intervals. N=700,751 children (sons and daughters).

The top panel in Figure 4 shows the estimated GP coefficient across the set of 126 models, ranked from lower to higher, whereas the bottom panel shows the ingredients of each model. Our preferred estimate of 0.027 is easily doubled in data of even quite high quality, for example in a model without measurement error but with $P$ variables somewhat coarsely measured. ${ }^{1}$ Even more worryingly, a (not uncommon) data set with income measured in bands, for fathers only, and with some error returns a comparatively strong net association of about 0.10 . Almost any deviation from our preferred model contributes to lifting the association to a level that many would find hard to ignore. 

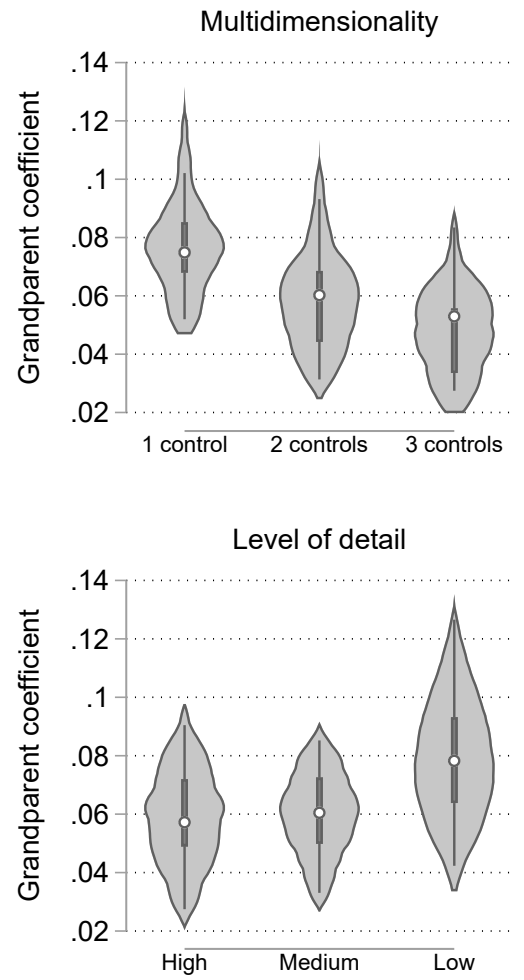
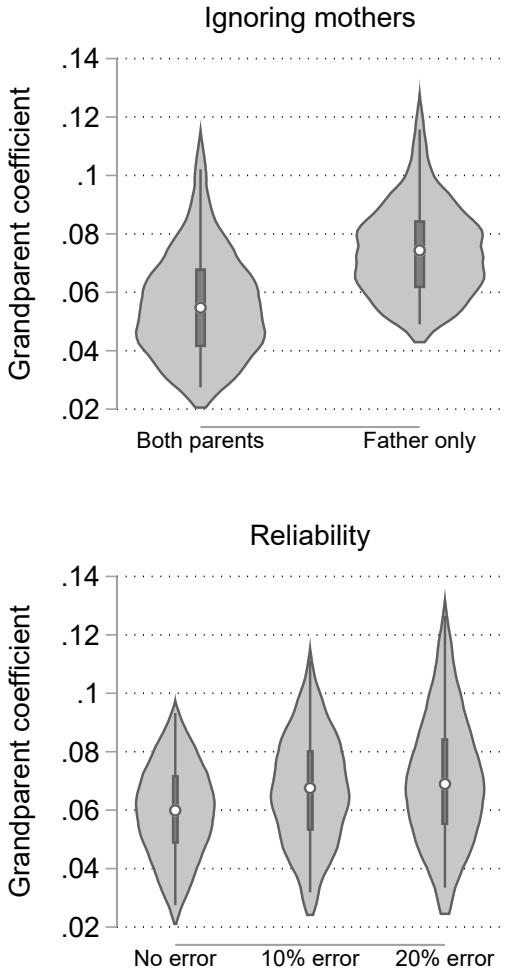

Figure 5: Distribution of net GP association with $C$ earnings, conditional on model components. Note: The figure shows the density distribution of point estimates for the net association between GP income and $C$ earnings from a set of 126 alternative models, separated by various model components. Top left: number of status dimensions controlled (all or a subset of $P$ earnings, occupation, and education). Top, right: number of parents covered (both, fathers only). Bottom, left: level of detail (high, medium, low). Bottom, right: amount of imputed error (none, 10 percent, or 20 percent). Dots indicate the median; boxes the interquartile range. Income and earnings have been $z$-standardized so that estimates reflect correlations. All models include controls for parent age and age squared, and child birth cohort and gender. $\mathrm{N}=700,751$ children (sons and daughters).

Although the 126 models in Figure 4 contain many combinations that can be identified in existing studies (see Table S3 in the online supplement), it is perhaps more illuminating to study the distribution of estimates, conditioning on one operational choice at a time. This we do in Figure 5, where results can be used to show which types of deviations from the ideal model produce the most overestimated GP effects.

Figure 5 shows the density distribution of point estimates for the net GP-C association separated by the number of status dimensions controlled (top, left), the number of parents covered (top, right), the level of measurement (bottom, left), and amount of imputed error (bottom, right). Dots indicate the median, whereas the bars indicate the interquartile range. Ignorance of multiple status dimensions and mothers appear to be most consequential. As for the scale level, the rank trans- 
formation produces correlations of a similar size as metric variables. Coarsening measures to the level of quintiles (and binary indicators for education/class) raises the size of the net GP association quite dramatically. In contrast, measurement error (within our probably conservative range) does not appear to create big problems, although it increases the dispersion of estimates and hence the upper bound for the GP estimate.

\section{Conclusion}

The last decade has seen a growth of interest in multigenerational processes in the transmission of advantage (Pfeffer 2014; Anderson et al. 2018). Many studies have shown that status-whether measured as education, earnings, occupation, or wealth-tends to persist within families to a greater degree than a first-order one-dimensional Markov process would suggest. Our study is no exception. We find that the correlation between GP income and $C$ earnings is roughly twice what we would expect by extrapolating from the two-generation association. Taken on its own, this evidence is consistent with the idea that grandparents exert a direct influence on status attainment. But it is consistent with many other models too (Lundberg 2020; Stuhler 2014). We have subjected the three-generation model to a more stringent test than has hitherto been possible and found that all this excess persistence can plausibly arise from failure to observe salient differences between parents.

Our analysis establishes four facts that should caution against overinterpreting residual GP-C associations. First, and perhaps least surprising, much of the association disappears in our data once we take a multidimensional view of stratification and give mothers their due recognition. Second, inspection of personal traits in the middle generation - here, fathers' cognitive ability-shows that even a model that controls extensively for both parents' education, earnings, occupation, and wealth still suffers from omitted variable bias that inflates the GP-C association. Third, one of the few robust results from this work-that of "compensating" effects of GP status at low levels of $P$ status (Anderson et al. 2018) - emerges as a consequence of the greater difficulty of observing status accurately at the lower end of the distribution. Fourth, by mimicking the quality of common survey data sets it is possible to generate results that span much of the range of previous work. That the size of the estimated GP coefficient depends inversely on data quality is an important finding, as it is one that meta-analysis has failed to detect (Anderson et al. 2018).

In light of the mixed results in the literature, much current work has shifted focus from asking whether grandparents influence grandchildren in the general population to addressing a set of more specific questions about when, why, and how influence may be heightened. Much of this effort targets conditions where the likelihood of contact is greater: for example, with greater residential proximity (Bol and Kalmijn 2016; Zeng and Xie 2014) or overlap in lifespans (Braun and Stuhler 2017; Sheppard and Monden 2017). We have not tested for these interactions here, but Dribe and Helgertz (2019) do so using similar data as ours and fail to find any support for these hypotheses. Likewise, Anderson et al. (2018:136) conclude in their comprehensive review that, with a few notable exceptions, "there 
have been consistent null results" for this idea. It therefore seems that, except in specific cultural contexts (Zeng and Xie 2014), further exploration of this "contact hypothesis" has limited promise.

Does this mean that we should abandon the multigenerational agenda as set out in Mare's (2011) presidential address? Such a conclusion would be premature, but perhaps not for the obvious reasons. An immediate objection is that our results pertain to a specific time and place: although grandparents may contribute little in contemporary Sweden, the same may not hold for other countries, time periods, or subpopulations. This is no doubt true, but fails to notice the wider point we have illustrated of just how sensitive common models of "grandparent effects" are to insufficient data. To be clear, we are not claiming that grandparents never contribute to their grandchildren's economic well-being or status attainment; it is just that existing studies do not provide compelling evidence on that point. Therefore, although we cannot and would not rule out a direct influence of grandparents in other contexts, our findings cast considerable doubt on the potential of standard designs to distinguish such influence from model artefacts.

We believe that research in this area should be careful to distinguish two strands of work: one on "grandparent effects" and one more broadly concerned with multigenerational mobility. The "grandparent effects" literature attempts to answer whether a coefficient on GP status enters positively into a multivariate regression and goes on to give that coefficient a causal interpretation. It is understandable that this interpretation has captivated sociologists, as it is both plausible and relatable: many of us have experienced deeply caring and meaningful relationships to kin beyond our nuclear family. The problem is that the research design used is not informative about this question, and wide variety in sample characteristics makes it difficult to compare results across studies. If the question is whether grandparents directly influence their grandchildren's attainments, more credible research designs are needed, including quasi-experimental designs. However, a narrow focus on causal inference fails to notice the full breadth of Mare's (2011) original agenda.

The long-run persistence of status matters regardless of whether that transmission occurs through parents or not. Earlier two-generation research has arguably been productive because it persevered in accumulating a broad base of comparable evidence (Goldthorpe 2005). From this perspective, the first problem about the grandparent literature is that it lacks coherence: whether the GP coefficient reaches significance or not is simply too dependent on arbitrary sample characteristics to build a cumulative evidence base. More robust metrics include bivariate status correlations across various degrees of kinship or the decay of such correlations across multiple generations (Braun and Stuhler 2017; Lundberg 2020). Work is also needed to flesh out the differences between various models, including those based on surnames (Santavirta and Stuhler 2019; Torche and Corvalan 2018) or dynastic models that aggregate information across individuals (Adermon, Lindahl, and Palme 2019; Hällsten and Kolk 2019). Given the increased availability of historical microdata (Song and Campbell 2017; Song et al. 2020) there is scope for much more research in this vein in the years to come. 


\section{Notes}

1 To keep this analysis tractable, we have not included $P$ wealth, which explains why the preferred estimate is slightly larger than in our main analysis.

\section{References}

Adermon, Adrian, Mikael Lindahl, and Mårten Palme. 2019. “Dynastic Human Capital, Inequality and Intergenerational Mobility." IZA Discussion Paper No. 12300, Institute of Labor Economics, Bonn. http://ftp.iza.org/dp12300.pdf.

Adermon, Adrian, Mikael Lindahl, and Daniel Waldenström. 2018. "Intergenerational Wealth Mobility and the Role of Inheritance: Evidence from Multiple Generations." Economic Journal 128(612):F482-13. https://doi .org/10.1111/ecoj . 12535.

Anderson, Lewis R., Paula Sheppard, and Christiaan Monden. 2018. “Grandparent Effects on Educational Outcomes: A Systematic Review." Sociological Science 5:114-42. https : //doi.org/10.15195/v5.a6.

Atkinson, Anthony B. 1981. “On Intergenerational Income Mobility in Britain." Journal of Post Keynesian Economics 3(2):194-18. https : //doi . org/10.1080/01603477.1980.11489214.

Becker, Gary S., and Nigel Tomes. 1979. "An Equilibrium Theory of the Distribution of Income and Intergenerational Mobility." Journal of Political Economy 87(6):1153-89. https://doi.org/10.1086/260831.

Beller, Emily. 2009. "Bringing Intergenerational Social Mobility Research into the TwentyFirst Century: Why Mothers Matter." American Sociological Review 74(4):507-28. https : //doi.org/10.1177/000312240907400401.

Bengtson, Vern L. 2001. "Beyond the Nuclear Family: The Increasing Importance of Multigenerational Bonds." Journal of Marriage and Family 63(1):1-16. https://doi.org/10. $1111 / \mathrm{j} .1741-3737.2001 .00001 . \mathrm{x}$.

Berkson, Joseph. 1946. "Limitations of the Application of Fourfold Table Analysis to Hospital Data." Biometrics Bulletin 2(3):47-53. https ://doi .org/10.2307/3002000.

Bingley, Paul, and Alessandro Martinello. 2014. "Measurement Error in the Survey of Health, Ageing and Retirement in Europe: A Validation Study with Administrative Data for Education Level, Income and Employment." SHARE Working Paper Series 16-2014.

Björklund, Anders, Jesper Roine, and Daniel Waldenström. 2012. “Intergenerational Top Income Mobility in Sweden: Capitalist Dynasties in the Land of Equal Opportunity?" Journal of Public Economics 96(5-6):474-84. https://doi .org/10.1016/j . jpubeco. 2012. 02.003.

Bohrnstedt, George W., and T. Michael Carter. 1971. "Robustness in Regression Analysis." Sociological Methodology 3:118-46. https://doi .org/10.2307/270820.

Bol, Thijs, and Matthijs Kalmijn. 2016. “Grandparents' Resources and Grandchildren's Schooling: Does Grandparental Involvement Moderate the Grandparent Effect?" Social Science Research 55:155-70. https ://doi .org/10.1016/j . ssresearch.2015 .09.011.

Bratsberg, Bernt, Knut Røed, Oddbjørn Raaum, Robin Naylor, Markus Jäntti, Tor Eriksson, and Eva Österbacka. 2007. "Nonlinearities in Intergenerational Earnings Mobility: Consequences for Cross-Country Comparisons." Economic Journal 117(519):C72-C92. https://doi.org/10.1111/j.1468-0297.2007.02036.x. 
Braun, Sebastian Till, and Jan Stuhler. 2017. "The Transmission of Inequality across Multiple Generations: Testing Recent Theories with Evidence from Germany." Economic Journal 128(609):576-611. https://doi.org/10.1111/ecoj.12453.

Breen, Richard. 2018. "Some Methodological Problems in the Study of Multigenerational Mobility." European Sociological Review 34(6):603-11. https://doi.org/10.1093/esr/ jcy037.

Breen, Richard, and Jan O. Jonsson. 1997. "How Reliable Are Studies of Social Mobility? An Investigation into the Consequences of Errors in Measuring Social Class." Research in Social Stratification and Mobility 15:91-112.

Breen, Richard, and Jan O. Jonsson. 2005. "Inequality of Opportunity in Comparative Perspective: Recent Research on Educational Attainment and Social Mobility." Annual Review of Sociology 31:223-43. https://doi .org/10.1146/annurev . soc.31.041304.122232.

Chan, Tak Wing, and Vikki Boliver. 2013. "The Grandparents Effect in Social Mobility: Evidence from British Birth Cohort Studies." American Sociological Review 78(4):662-78. https://doi.org/10.1177/0003122413489130.

Deindl, Christian, and Nicole Tieben. 2016. "Resources of Grandparents: Educational Outcomes across Three Generations in Europe and Israel." Journal of Marriage and Family 79(3):769-83. https://doi.org/10.1111/jomf . 12382.

Dribe, Martin, and Jonas Helgertz. 2016. “The Lasting Impact of Grandfathers: Class, Occupational Status, and Earnings over Three Generations in Sweden 1815-2011." Journal of Economic History 76(4):969-1000. https : //doi .org/10.1017/S0022050716000991.

Dribe, Martin, and Jonas Helgertz. 2019. “Do Grandfathers Really Matter for Social Mobility? Evidence from Swedish Register Data." Lund Papers in Economic Demography 2019:1. Centre for Economic Demography, School of Economics and Management, Lund University. https://www.ed.lu.se/media/ed/papers/working_papers/LPED_2019_1.pdf.

Erikson, Robert, 1984. "Social Class of Men, Women and Families." Sociology 18(4):500-14. https://doi.org/10.1177/0038038584018004003.

Erikson, Robert, and John H. Goldthorpe. 1992. The Constant Flux: A Study of Class Mobility in Industrial Societies. Oxford: Clarendon Press.

Goldberger, Arthur S. 1989. "Economic and Mechanical Models of Intergenerational Transmission." American Economic Review 79(3):504-13.

Goldthorpe, John H. 2005. "Progress in Sociology: The Case of Social Mobility Research." Pp. 56-82 in Analyzing Inequality: Life Chances and Social Mobility in Comparative Perspective, edited by Stefan Svallfors. Stanford: Stanford University Press.

Hodge, Robert W. 1966. “Occupational Mobility as a Probability Process." Demography 3(1):19-34. https://doi.org/10.2307/2060061.

Hout, Michael, 2018. "Americans' Occupational Status Reflects the Status of Both of Their Parents." Proceedings of the National Academy of Sciences 115(38):9527-32. https://doi . org/10.1073/pnas.1802508115.

Hällsten, Martin, and Martin Kolk. 2019. “The Shadow of Peasant Past: Seven Generations of Inequality Persistence in Northern Sweden." SocArXiv, 29 Jan. 2020. https://doi. org/10.31235/osf.io/yjksz

Hällsten, Martin, and Fabian T. Pfeffer. 2017. “Grand Advantage: Family Wealth and Grandchildren's Educational Achievement in Sweden." American Sociological Review 82(2):328-60. https://doi.org/10.1177/0003122417695791.

Jæger, Mads Meier. 2012. “The Extended Family and Children's Educational Success.” American Sociological Review 77(6):903-22. https : //doi .org/10.1177/0003122412464040. 
Jonsson, Jan O. 2001. “Towards a Post-Fordist Life-Course Regime? Generational Changes in Transitions and Volatility." Pp. 1-28 in Cradle to Grave: Life-Course Changes in Modern Sweden, edited by Jan O. Jonsson and Colin Mills. Abingdon-on-Thames, UK: Routledge.

Jonsson, Jan O., David B. Grusky, Matthew Di Carlo, Reinhard Pollak, and Mary C. Brinton. 2009. "Micro-Class Mobility: Social Reproduction in Four Countries." American Journal of Sociology 114(4):977-1036. https : //doi .org/10.1086/596566.

Killewald, Alexandra, Fabian T. Pfeffer, and Jared Schachner. 2017. "Wealth Inequality and Accumulation." Annual Review of Sociology 43:379-404. https ://doi .org/10.1177/ 0003122412464040.

Knigge, Antonie. 2016. "Beyond the Parental Generation: The Influence of Grandfathers and Great-Grandfathers on Status Attainment." Demography 53(4):1219-44. https://doi . org/10.1007/s13524-016-0486-6.

Laurison, Daniel, and Sam Friedman. 2016. “The Class Pay Gap in Higher Professional and Managerial Occupations." American Sociological Review 81(4):668-95. https : //doi .org/ 10.1177/0003122416653602.

Lindahl, Mikael, Mårten Palme, Sofia Sandgren Massih, and Anna Sjögren. 2015. “LongTerm Intergenerational Persistence of Human Capital: An Empirical Analysis of Four Generations." Journal of Human Resources 50(1):1-33. https://doi .org/10.3368/jhr. 50.1.1.

Liu, Hexuan. 2018. "Social and Genetic Pathways in Multigenerational Transmission of Educational Attainment." American Sociological Review 83(2):278-304. https : //doi .org/ 10.1177/0003122418759651.

Lundberg, Ian D. 2020. “Does Opportunity Skip Generations? Reassessing Evidence from Sibling and Cousin Correlations." Demography, forthcoming.

Mare, Robert D. 2011. "A Multigenerational View of Inequality." Demography 48(1):1-23. https://doi.org/10.1007/s13524-011-0014-7.

Modin, Bitte, Robert Erikson, and Denny Vågerö. 2013. “Intergenerational Continuity in School Performance: Do Grandparents Matter?" European Sociological Review 29(4):858-70. https://doi .org/10.1093/esr/jcs064.

Modin, Bitte, and Johan Fritzell. 2009. "The Long Arm of the Family: Are Parental and Grandparental Earnings Related to Young Men's Body Mass Index and Cognitive Ability?" International Journal of Epidemiology 38(3):733-44. https : //doi .org/10.1093/ije/dyp001.

Mood, Carina. 2017. "More Than Money: Social Class, Income, and the Intergenerational Persistence of Advantage." Sociological Science 4:263-87. https://doi.org/10.15195/ v4.a12.

Mukherjee, Ramkrishna. 1954. "A Study of Social Mobility between Three Generations.” Pp. 266-90 in Social Mobility in Britain, edited by D. V. Glass. London: Routledge Kegan Paul.

Pearce, Neil, and Lorenzo Richiardi. 2014. "Three Worlds Collide: Berkson's Bias, Selection Bias and Collider Bias." International Journal of Epidemiology 43(2):521-24. https : //doi . org/10.1093/ije/dyu025.

Pearl, Judea. 2000. Causality: Models, Reasoning and Inference. Cambridge: Cambridge University Press.

Pfeffer, Fabian T. 2014. "Multigenerational Approaches to Social Mobility: A Multifaceted Research Agenda." Research in Social Stratification and Mobility 35:1-12. https://doi. org/10.1016/j.rssm.2014.01.001.

Pilkauskas, Natasha V., and Christina Cross. 2018. "Beyond the Nuclear Family: Trends in Children Living in Shared Households." Demography 55(6):2283-97. https ://doi .org/ 10.1007/s13524-018-0719-y. 
Pohl, Richard, and Jeanine Soleilhavoup. 1982. "La transmission du statut social sur deux ou trois générations." Economie et statistique 144(1):25-42. https://doi .org/10.3406/ estat.1982.4614.

Santavirta, Torsten, and Jan Stuhler. 2019. "Name-Based Estimators of Intergenerational Mobility: Evidence from Finnish Veterans." Paper presented at the 2019 Society of Labor Economists (SOLE) Annual Meeting, Arlington. https://tsantavirta.com/ wp-content/uploads/2019/09/Santavirta_Stuhler_Names_0911.pdf.

Sewell, William H., and Robert M. Hauser. 1975. Education, Occupation, and Earnings: Achievement in the Early Career. New York: Academic Press.

Sheppard, Paula, and Christiaan Monden. 2018. “The Additive Advantage of Having Educated Grandfathers for Children's Education: Evidence from a Cross-National Sample in Europe." European Sociological Review 34(4):365-80. https ://doi .org/10.1093/esr/ jcy026.

Simonsohn, Uri, Joseph P. Simmons, and Leif D. Nelson. 2015. “Specification Curve: Descriptive and Inferential Statistics on All Reasonable Specifications." Available at SSRN: https://doi.org/10.2139/ssrn. 2694998.

Solon, Gary. 2014. "Theoretical Models of Inequality Transmission across Multiple Generations." Research in Social Stratification and Mobility 35:13-18. https ://doi .org/10.1016/ j.rssm.2013.09.005.

Song, Xi. 2016. "Diverging Mobility Trajectories: Grandparent Effects on Educational Attainment in One- and Two-Parent Families in the United States." Demography 53(6):190532. https://doi.org/10.1007/s13524-016-0515-5.

Song, Xi, and Cameron D. Campbell. 2017. "Genealogical Microdata and Their Significance for Social Science." Annual Review of Sociology 43:75-99. https://doi .org/10.1146/ annurev-soc-073014-112157.

Song, Xi, and Robert D. Mare. 2017. "Short-Term and Long-Term Educational Mobility of Families: A Two-Sex Approach." Demography 54(1):145-73. https://doi .org/10.1073/ pnas. 1905094116.

Song, Xi, Catherine G. Massey, Karen A. Rolf, Joseph P. Ferrie, Jonathan L. Rothbaum, and $\mathrm{Yu}$ Xie. 2020. "Long-Term Decline in Intergenerational Mobility in the United States since the 1850s." Proceedings of the National Academy of Sciences 117(1):251-58. https://doi.org/10.1073/pnas.1905094116.

Stuhler, Jan. 2014. "Mobility Across Multiple Generations: The Iterated Regression Fallacy." IZA Discussion Paper No. 7072, Institute of Labor Economics (IZA), Bonn, Germany.

Svalastoga, Kaare. 1959. Prestige, Class, and Mobility. Toronto: William Heinemann Ltd.

Torche, Florencia, and Alejandro Corvalan. 2018. "Estimating Intergenerational Mobility with Grouped Data: A Critique of Clark's The Son Also Rises." Sociological Methods $\mathcal{E}$ Research 47(4):787-811. https : //doi .org/10.1177/0049124116661579.

Treiman, Donald J. 1977. Occupational Prestige in Comparative Perspective. New York Academic Press.

Warren, John R., and Robert M. Hauser. 1997. "Social Stratification across Three Generations: New Evidence from the Wisconsin Longitudinal Study." American Sociological Review 62(4):561-72. https: //doi.org/10.2307/2657426.

Young, Cristobal, and Katherine Holsteen. 2017. "Model Uncertainty and Robustness: A Computational Framework for Multimodel Analysis." Sociological Methods E Research 46(1):3-40. https://doi.org/10.1177/0049124115610347. 
Zeng, Zhen, and Yu Xie. 2014. "The Effects of Grandparents on Children's Schooling: Evidence from Rural China." Demography 51(2):599-617. https://doi.org/10.1007/ s13524-013-0275-4.

Acknowledgments: This work received funding from the Swedish Research Council for Health, Working Life, and Welfare (FORTE), grant no. 2016-07099. The first author also acknowledges support from Nuffield College and the Leverhulme Centre for Demographic Science, The Leverhulme Trust. Previous versions of this study have been circulated under the title "Putting the Grandparents to Rest: False Positives in Multigenerational Mobility Research" and presented at the Swedish Institute for Social Research, the European Consortium for Sociological Research (ECSR) Conference in Paris 2018, and the Population Association of America (PAA) Annual Meeting in Austin 2019. We thank participants at these occasions, in particular Robert Erikson, Sara Kjellsson, Simon Hjalmarsson, Are Skeie Hermansen, and Florencia Torche, for helpful comments and criticism. Thanks also to the Editor, Deputy Editor, and Consulting Editor at Sociological Science who handled our manuscript. Any errors remain our own.

Per Engzell: Nuffield College and Leverhulme Centre for Demographic Science, University of Oxford; Swedish Institute for Social Research, Stockholm University. E-mail: per.engzell@nuffield.ox.ac.uk.

Carina Mood: Swedish Institute for Social Research, Stockholm University; Institute for Futures Studies, Stockholm. E-mail: carina.mood@sofi.su.se.

Jan 0. Jonsson: Nuffield College and Leverhulme Centre for Demographic Science, University of Oxford; Swedish Institute for Social Research, Stockholm University; Institute for Futures Studies, Stockholm. E-mail: janne.jonsson@nuffield.ox.ac.uk. 